\title{
(6) OPEN ACCESS \\ TRAIL and TRAIL receptors splice variants during long-term interferon $\beta$ treatment of patients with multiple sclerosis: evaluation as biomarkers for therapeutic response
}

\author{
Carlos López-Gómez, ${ }^{1}$ Begoña Oliver-Martos, ${ }^{1}$ María-Jesús Pinto-Medel, ${ }^{1}$ \\ Margarita Suardiaz, ${ }^{1}$ Virginia Reyes-Garrido, ${ }^{2}$ Patricia Urbaneja, ${ }^{2}$ Óscar Fernández, ${ }^{2}$ \\ Laura Leyva $^{1}$
}

${ }^{1}$ Research Laboratory, UGCI Neurociencias Clínicas, Instituto de Investigación Biomédica de Málaga (IBIMA), Hospital Regional Universitario de Málaga/Universidad de Málaga, Málaga, Spain ${ }^{2}$ Department of Neurology, UGCI Neurociencias Clínicas, Instituto de Investigación Biomédica de Málaga (IBIMA), Hospital Regional Universitario de Málaga/Universidad de Málaga, Málaga, Spain

\section{Correspondence to Dr Laura Leyva, Hospital Regional Universitario de Málaga, Laboratorio de Investigación, Hospital Civil, pabellón 5 sótano, Plaza de Hospital Civil s/n, Málaga 29009, Spain leyvafer@gmail.com}

OF and LL contributed equally to this study.

Received 17 November 2014 Revised 20 January 2015 Accepted 6 February 2015

Published Online First 3 March 2015

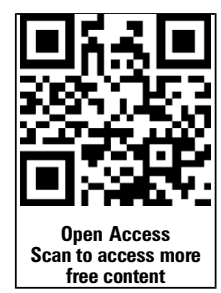

CrossMark

To cite: López-Gómez $C$ Oliver-Martos B, PintoMedel M-J, et al. J Neurol Neurosurg Psychiatry 2016:87:130-137.
ABSTRACT

Objective We aimed to assess the effects of interferon $\beta$ (IFN $\beta$ ) treatment on the expression of the splice variants of the Tumour necrosis factor-Related Apoptosis Inducing Ligand (TRAIL) and its receptors in different cell subpopulations (CD14+, CD4+ and CD8+) from patients with multiple sclerosis (MS), and to determine whether this expression discriminated responders from nonresponders to IFN $\beta$ therapy.

Methods We examined mRNA expression of the TRAIL and TRAIL receptors variants in patients with MS, at baseline and after one year of IFN $\beta$ therapy, according to responsiveness to this drug.

Results Long-term therapy with IFN $\beta$ increased the expression of TRAIL- $\alpha$ in T cell subsets exclusively from responders and decreased the expression of the isoform 2 of TRAILR-2 in monocytes from responders as well as non-responders. Lower expression of TRAIL- $\alpha$, and higher expression of TRAIL- $\beta$ in monocytes and T cells, was found before the onset of IFN $\beta$ therapy in patients who will subsequently become responders. Baseline expression of TRAILR-1 was also significantly higher in monocytes and CD4+ T cells from responders.

Conclusions The present study shows that long-term IFN $\beta$ treatment has a direct influence on TRAIL- $\alpha$ and TRAILR-2 isoform 2 expression. Besides, receiver operating characteristic analysis revealed that the baseline expression of TRAIL- $\alpha$ in monocytes and T cells, and that of TRAILR-1 in monocytes and CD4+ T cells, showed a predictive value of the clinical response to IFN $\beta$ therapy, pointing to a role of TRAIL system in the mechanism of action of IFN $\beta$ in MS that will need further investigation.

\section{INTRODUCTION}

Recombinant interferon $\beta$ (IFN $\beta$ ) is one of the most widely used first line therapies in multiple sclerosis (MS), but up to $50 \%$ of patients under treatment continue to experience relapses and progression of the disease and are considered suboptimal responders. ${ }^{1}$ It is, therefore, strongly desirable to count with biomarkers that allow prediction of the therapeutic response to IFN $\beta$.

The Tumour necrosis factor-Related Apoptosis Inducing Ligand (TRAIL)/TRAIL Receptor System has been shown to be implicated in MS pathogen$\mathrm{esis}^{2-4}$ as well as in the mechanisms of action of
IFN $\beta .{ }^{5}{ }^{6}$ Expression of TRAIL and its four surface receptors in different cell types during IFN $\beta$ treatment has been studied, ${ }^{78}$ and TRAIL mRNA expression in leucocytes has been proposed as a biomarker for the therapeutic response to IFN $\beta$ in patients with MS. ${ }^{5}$ Nevertheless, none of these studies has taken into account the different splicing variants of each gene, which could lead to the expression of nonfunctional proteins. Three different splice variants have been discovered for TRAIL: TRAIL- $\alpha$, the functional isoform; TRAIL- $\beta$, which lacks exon 3 ; and TRAIL- $\gamma$, which lacks exon 2 and 3 . The loss of exon 3 leads to the lack of the extracellular domain and, therefore, to the absence of apoptotic potential. ${ }^{9}$ TRAILR-2 has two different apoptotic variants: TRAILR-2 isoform 1 (TRICK2b), which has an 87 nucleotides insertion and TRAILR-2 isoform 2 (TRICK2a), which is homologous to TRAILR-1. ${ }^{10}$ Finally, there are two different splice variants for TRAILR-4: TRAILR-4 $\alpha$, the long isoform, and TRAILR-4 $\beta$, which lacks exon $3 .^{11}$ The loss of this exon leads to the truncation of the first cysteine rich domain 1 , involved in the ligand-receptor complex, which may alter its ability to bind TRAIL.

In this study, we monitored the expression kinetics of TRAIL and its receptors after induction with IFN $\beta$. Although kinetics of TRAIL expression have previously been reported, ${ }^{12}$ it remains unknown whether TRAIL receptors follow the same pattern.

The aim of the present work was to assess the effects of IFN $\beta$ treatment on the expression of the splice variants of TRAIL and its receptors in different cell subpopulations from patients with MS, and to determine whether these expressions discriminated responders from non-responders to IFN $\beta$ therapy.

\section{METHODS}

Subjects

Forty-two Spanish patients with MS prone to start IFN $\beta$ treatment were recruited from the Multiple Sclerosis Unit at Malaga Regional University Hospital (Malaga, Spain) and followed for a minimum of 2 years of treatment.

Study inclusion criteria included definite MS according to the McDonald criteria, ${ }^{13}$ and treatment-naive at baseline for at least 6 months. 
Once they started therapy with IFN $\beta$, patients had to be on a stable dose for at least 24 months.

Blood samples were obtained during remissions before the first IFN $\beta$ administration (baseline) and again after 12-14 months (serum and peripheral blood mononuclear cells (PBMC)) and 24 months (serum) on that therapy.

As controls (HC), twenty age-matched healthy unrelated subjects were selected.

Samples were processed following standard procedures and frozen immediately after they were received by the Málaga Regional Hospital Biobank, as part of Andalusian Public Health System Biobank. All individuals participating in the study gave their informed consent and protocols were approved by an institutional ethical committee (Comisión de Ética y de Investigación del Hospital Regional Universitario Carlos Haya).

Two patients initially taking part in the study were excluded due to the presence of high and permanent titres of neutralising antibodies (NAbs) against IFN $\beta$. The demographic and clinical variables of the remaining 40 patients with MS and $\mathrm{HC}$ are listed in table 1 .

\section{Definition of response to IFN $\beta$ therapy}

Patients were classified as optimal responders if they had neither relapses within the previous year nor progression of the disease over the same follow-up period, and as non-responders if they experienced one or more relapses or an increase of at least one point in the Expanded Disability Status Scale (EDSS) that persisted for a minimum of two consecutive visits separated by a 6-month interval. ${ }^{14}$

\section{Detection of Neutralising Antibodies NABs}

The presence of NAbs in serum was checked after 12 and 24 months of treatment by the IFN-induced inhibition of virus cytopathic effect on human cells in culture, following the WHO recommendations as previously described. ${ }^{15}$ The neutralisation titre of serum samples was calculated according to Kawade et al. ${ }^{16}$ Titres $\geq 20 \mathrm{TRU} / \mathrm{mL}$ were considered as positive.

\section{Determination of expression kinetics in the Jurkat T-cell}

leukaemia cell line

Owing to the limited yield of PBMC obtained from each patient, gene expression kinetics were carried out in an immortalised human $\mathrm{T}$ lymphoblastoid cell line. Jurkat cells (Clone
E.6, American Type Culture Collection) were cultured in 12 -well plates, at $1.5 \times 10^{6}$ cells $/ \mathrm{mL}$, in RPMI 1640 medium supplemented with $10 \%$ fetal bovine serum (FBS), 1.3\% Hepes, $50 \mu \mathrm{g} / \mathrm{mL}$ gentamicin and $2 \mathrm{mM}$ L-glutamine. After incubation at $37^{\circ} \mathrm{C}$ and $5 \% \mathrm{CO}_{2}$ for $24 \mathrm{~h}$, cells were washed and incubated for $2 \mathrm{~h}$ with the former media without FBS. Cells for pre-stimulation condition (3 replicates) were collected in $1 \mathrm{~mL}$ of Tripure Isolation Reagent (Roche Diagnostic $\mathrm{GmbH}$ ) and the remaining cells were stimulated with $200 \mathrm{UI} / \mathrm{mL}$ of IFN $\beta-1$ a (Avonex, Biogen Idec) and collected in the same way at 4, 8, 12 and $24 \mathrm{~h}$ after IFN $\beta$ induction.

\section{Gene expression in patients with MS}

Blood samples were taken before the first IFN $\beta$ administration and after 1 year of treatment. PBMC were isolated by a Ficoll-Hypaque density gradient. Monocytes (CD14+), CD4+ $\mathrm{T}$ cells and CD8 $+\mathrm{T}$ cells were isolated using immunomagnetic microbeads and LS MACS columns (Miltenyi Biotec GmbH), following the manufacturer's protocol. Purity of each cellular subset (95-97\%) was assessed by flow cytometry. After isolation, the cellular subsets were cultured in 96 well plates with medium without FBS. Cells were induced with $200 \mathrm{UI} / \mathrm{mL}$ of IFN $\beta-1$ a and collected in Tripure at 4 and $24 \mathrm{~h}$ after induction.

\section{RNA isolation, primer design and quantitative reverse transcription PCR}

Total RNA was isolated from Jurkat cells and PBMC using a modification of the phenol-chloroform method. ${ }^{17}$ Total RNA yield and quality of product was assessed with a Nanodrop 2000 Spectrophotometer.

For complementary DNA (cDNA) synthesis, $1 \mu \mathrm{g}$ of total RNA was reverse transcribed with the M-MLV reverse transcriptase as described elsewhere. ${ }^{18}$ The cDNA was stored at $-80^{\circ} \mathrm{C}$ until use.

Primers for all amplified products are shown in table 2. Primers for TRAILR-1 and TRAILR-3 were designed using Primer 3 software. ${ }^{19}$ Primers for TRAIL, TRAILR-2 and TRAILR-4 were custom designed to make them complementary to the specific exon boundaries of each splice variant.

Conventional PCR with temperatures ranging from $57^{\circ} \mathrm{C}$ to $63^{\circ} \mathrm{C}$ were performed to ensure specificity of primer pairs and to determine the optimal annealing temperature. Annealing at

Table 1 Demographic and clinical characteristics of the participants at baseline

\begin{tabular}{|c|c|c|c|c|}
\hline Characteristics & $\begin{array}{l}\text { Healthy controls } \\
n=20\end{array}$ & $\begin{array}{l}\text { Responders } \\
n=24\end{array}$ & $\begin{array}{l}\text { Non-responders } \\
n=16\end{array}$ & p Values* \\
\hline Female/male ratio ( $\%$ women) & $14 / 6(70)$ & $17 / 7(70.8)$ & $12 / 4(75)$ & 0.867 \\
\hline Age at baseline (years) & $34.0(31.7-43.5)$ & $34.5(28.5-45.7)$ & $34.0(29.2-46.0)$ & 0.950 \\
\hline Duration of disease & & $4.0(2.0-7.7)$ & $5.0(3.2-6.7)$ & 0.774 \\
\hline RR/SP ratio (\% RR) & & $22 / 2(91.7)$ & $15 / 1(93.8)$ & 1.000 \\
\hline EDSS at baseline & & $1.0(1.0-1.37)$ & $1.25(1.0-2.87)$ & 0.101 \\
\hline Number of relapses in the 2 previous years & & $1.0(1.0-2.0)$ & $2.0(1.0-2.0)$ & 0.149 \\
\hline \multicolumn{5}{|l|}{ Type of IFN $\beta$} \\
\hline Intramuscular IFN $\beta-1 \mathrm{a}(\%)$ & & $4(16.7)$ & $1(6.2)$ & 0.422 \\
\hline Subcutaneous IFN $\beta-1$ a (\%) & & 19 (79.2) & $13(81.3)$ & \\
\hline Subcutaneous IFN $\beta-1 \mathrm{~b}(\%)$ & & $1(4.1)$ & $2(12.5)$ & \\
\hline
\end{tabular}


Table 2 Primers used for amplification of the splice variants of TRAIL and TRAIL receptors

\begin{tabular}{|c|c|c|c|c|}
\hline Product name & Primer & Sequence $5^{\prime} \rightarrow 3^{\prime}$ & Location & Product length (bp) \\
\hline TRAIL- $\alpha$ & $\begin{array}{l}\text { TRAIL-fwd1 } \\
\text { TRAIL-rev1 }\end{array}$ & $\begin{array}{l}\text { TTCTACAGTTCAAGAAAAGC } \\
\text { GCCCAGAGCCTTTTCATTCT }\end{array}$ & $\begin{array}{l}\text { Exons } 3-4 \text { joint } \\
\text { Exons } 4-5 \text { joint }\end{array}$ & 145 \\
\hline TRAIL- $\beta$ & $\begin{array}{l}\text { TRAIL-fwd2 } \\
\text { TRAIL-rev2 }\end{array}$ & $\begin{array}{l}\text { AGCTCGTTAGAAAGAAAAGC } \\
\text { CTCAGGAATGAATGCCCACT }\end{array}$ & $\begin{array}{l}\text { Exons } 2-4 \text { joint } \\
\text { Exon }\end{array}$ & 195 \\
\hline TRAIL- $\gamma$ & $\begin{array}{l}\text { TRAIL-fwd3 } \\
\text { TRAIL-rev1 }\end{array}$ & $\begin{array}{l}\text { ACGAGCTGAAGCAGAAAAGC } \\
\text { GCCCAGAGCCTTTTCATTCT }\end{array}$ & $\begin{array}{l}\text { Exons } 1-4 \text { joint } \\
\text { Exons } 4-5 \text { joint }\end{array}$ & 145 \\
\hline TRAILR-1 & $\begin{array}{l}\text { TRAILR1-fwd } \\
\text { TRAILR1-rev }\end{array}$ & $\begin{array}{l}\text { ACCAGGAACACAGCATGTCA } \\
\text { GTCACTCCAGGGCGTACAAT }\end{array}$ & $\begin{array}{l}\text { Exon } \\
\text { Exon }\end{array}$ & 132 \\
\hline TRAILR-2 isoform 1 & $\begin{array}{l}\text { TRAILR2-fwd } \\
\text { TRAILR2-rev1 }\end{array}$ & $\begin{array}{l}\text { CAGTGCGAAGAAGGCACCTT } \\
\text { CCCCACTGTGCTTTGTACCT }\end{array}$ & $\begin{array}{l}\text { Exon } 4 \\
87 \text { bp insertion in exon } 5\end{array}$ & 145 \\
\hline TRAILR-2 isoform 2 & $\begin{array}{l}\text { TRAILR2-fwd } \\
\text { TRAILR2-rev2 }\end{array}$ & $\begin{array}{l}\text { CAGTGCGAAGAAGGCACCTT } \\
\text { TGATGCCTGATTCTTTGTGG }\end{array}$ & $\begin{array}{l}\text { Exon } 4 \\
\text { Exon } 5\end{array}$ & 157 \\
\hline TRAILR-3 & $\begin{array}{l}\text { TRAILR3-fwd } \\
\text { TRAILR3-rev }\end{array}$ & $\begin{array}{l}\text { TGCACAGAGGGTGTGGATTA } \\
\text { GGTCATGGTGCAGGAACTIT }\end{array}$ & $\begin{array}{l}\text { Exon } \\
\text { Exon }\end{array}$ & 108 \\
\hline TRAILR-4 $\alpha$ & $\begin{array}{l}\text { TRAILR4-fwd1 } \\
\text { TRAILR4-rev }\end{array}$ & $\begin{array}{l}\text { CAATTTGCCTTCTTGCCTGC } \\
\text { CTCTGGGACACCCTGTTCTA }\end{array}$ & $\begin{array}{l}\text { Exon } 3 \\
\text { Exons } 4-5 \text { joint }\end{array}$ & 164 \\
\hline TRAILR-4 $\beta$ & $\begin{array}{l}\text { TRAILR4-fwd2 } \\
\text { TRAILR4-rev }\end{array}$ & $\begin{array}{l}\text { GGAGTGTCCAGCAGGTCAAA } \\
\text { CTCTGGGACACCCTGTTCTA }\end{array}$ & $\begin{array}{l}\text { Exons } 2-4 \text { joint } \\
\text { Exons } 4-5 \text { joint }\end{array}$ & 137 \\
\hline GADPH & $\begin{array}{l}\text { GADPH-fwd } \\
\text { GADPH-rev }\end{array}$ & $\begin{array}{l}\text { GAAGATGGTGATGGGATTTC } \\
\text { GAAGGTGAAGGTCGGAGT }\end{array}$ & $\begin{array}{l}\text { Exon } \\
\text { Exon }\end{array}$ & 225 \\
\hline
\end{tabular}

TRAIL, Tumour necrosis factor-Related Apoptosis Inducing Ligand.

$57^{\circ} \mathrm{C}$ was optimal for TRAILR-1 and TRAIL variants, at $60^{\circ} \mathrm{C}$ for $\mathrm{GAPDH}$ and at $58^{\circ} \mathrm{C}$ for the remaining genes.

Quantitative PCR was performed in duplicate in a Rotor Gene Q Thermocycler (Qiagen $\mathrm{GmbH}$ ) in a $20 \mu \mathrm{L}$ reaction mix containing DEPC-treated water, $20 \mathrm{mM}$ primers (forward and reverse), Quantitec SYBR Green PCR Master Mix (Qiagen) and cDNA. The programme consisted of a step of $15 \mathrm{~min}$ at $95^{\circ} \mathrm{C}$, followed by 40 cycles of $95^{\circ} \mathrm{C}$ for $30 \mathrm{~s}, 57^{\circ} \mathrm{C}, 58^{\circ} \mathrm{C}$ or $60^{\circ} \mathrm{C}$ for $30 \mathrm{~s}$ and $72^{\circ} \mathrm{C}$ for $30 \mathrm{~s}$. A melting step from $65^{\circ} \mathrm{C}$ to $95^{\circ} \mathrm{C}$ was run, increasing $0.5^{\circ} \mathrm{C}$ every $5 \mathrm{~s}$.

The relative TRAIL and TRAIL receptor variants messenger RNA (mRNA) expression levels were calculated according to the $2^{-\Delta \Delta C T}$ method, first by normalising to GAPDH and then to a calibrator sample.

\section{Statistical analysis}

Comparisons of demographic characteristics at baseline between $\mathrm{HC}$, responder and non-responder patients with MS were performed by Kruskal-Wallis test (age) and $\chi^{2}$ test (gender). Comparisons of clinical characteristics at baseline between responders and non-responders were performed by means of a Mann-Whitney U test (duration, EDSS and number of relapses) and $\chi^{2}$ or Fisher test (clinical course and type of IFN $\beta$ ).

A Wilcoxon test was used to compare relative expression between pretreatment samples and samples from patients after 1 year of treatment with IFN $\beta$.

A Mann-Whitney U test was used to compare relative expression of TRAIL and its receptors between responders and suboptimal responders to IFN $\beta$ therapy.

Receiver operating characteristic (ROC) analyses were performed to evaluate the predictive value of gene expression before treatment onset on therapeutic response to IFN $\beta$.

\section{RESULTS}

Gene expression kinetics of TRAIL and TRAIL receptors in Jurkat cells

The expression kinetics of each gene after in vitro induction with IFN $\beta$ was determined in Jurkat cells (figure 1). The three
TRAIL variants showed a similar expression pattern: gene expression was upregulated during $1-4 \mathrm{~h}$ after IFN $\beta$ stimulation (peak at $4 \mathrm{~h}$ ), and declined thereafter, followed by a second increment after $24 \mathrm{~h}$, in agreement with previous data. ${ }^{12}$

TRAILR-1 and TRAILR-2 shared the same expression pattern, characterised by a decreased expression in the first hours, and a peak $24 \mathrm{~h}$ after IFN $\beta$ induction. The decoy receptors also began to be induced at $8-12 \mathrm{~h}$ post-stimulation with IFN $\beta$, showing a progressive increment with a marked peak at 24 h. Thus, in PBMC, the expression of TRAIL and its receptors was assessed at 4 and $24 \mathrm{~h}$ after in vitro stimulation with IFN $\beta$, respectively.

\section{Gene expression of TRAIL and TRAIL receptors in untreated} patients with MS and HC

On in vitro stimulation with IFN $\beta$, mRNA expression of TRAIL- $\alpha$ was significantly increased in HC compared to untreated patients with MS in the three cellular subsets $(p=0.023$ in monocytes, $\mathrm{p}=0.00004$ in CD4 $+\mathrm{T}$ cells and $\mathrm{p}=0.021$ in CD8 $+\mathrm{T}$ cells), as observed in figure 2. We detected no other significant differences in the expression of TRAIL and receptor variants at the RNA level.

Basal gene expression of TRAIL and TRAIL receptors in patients with MS who will subsequently become responders or non-responders to IFN $\beta$ therapy

Within the patient group, prior to IFN $\beta$ treatment onset, we found higher mRNA expression of TRAIL- $\alpha$ in monocytes, CD4 + and CD8 + T cells from patients who will subsequently be classified as non-responders than from responders $(p=0.008$, $\mathrm{p}=0.00006$ and 0.003 , respectively), as shown in figure 3 . Conversely, the mRNA expression of the TRAIL- $\beta$ isoform was significantly higher in CD4 + and CD8 $+\mathrm{T}$ cells from patients who will become responders $(p=0.03$ and $p=0.025)$, and showed the same trend of expression in monocytes $(p=0.052)$. Additionally, expression of TRAILR-1 was also significantly higher in monocytes and CD4 $+\mathrm{T}$ cells from patients who will become responders. 
A

TRAIL

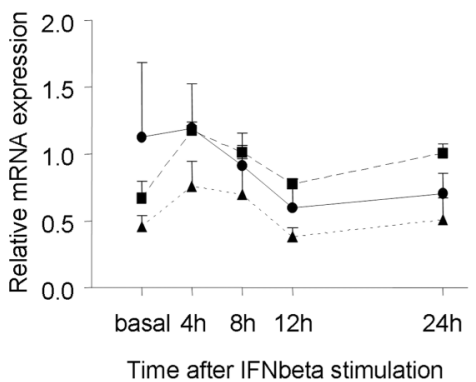

- TRAIL alpha

- TRAIL beta

- TRAIl gamma
B

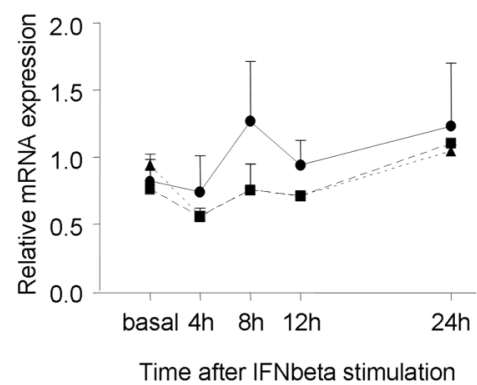

- TRAILR-1

- TRAILR-2 isoform 1

- TRAILR-2 isoform 2
C TRAIL Decoy Receptors

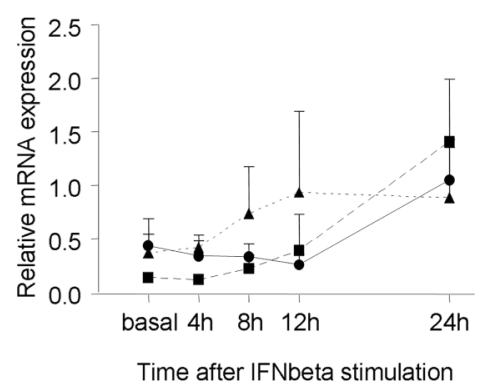

- TRAILR-3

- TRAILR-4 alpha

- TRAILR-4 beta

Figure 1 Gene expression kinetics of the Tumour necrosis factor-Related Apoptosis Inducing Ligand (TRAIL) and TRAIL receptors splicing variants in Jurkat cells on in vitro stimulation with interferon $\beta$ (IFN $\beta$ ). (A) TRAIL splicing variant genes are upregulated during 1-4 h of IFN $\beta$ treatment and decline thereafter. (B) Death receptor isoforms begin to upregulate at $8 \mathrm{~h}$ and reach a maximum at $24 \mathrm{~h}$. (C) Decoy receptor isoforms begin to be induced at the $12 \mathrm{~h}$ time point and beyond. Expression levels are represented as relative expression compared with the reference gene GAPDH, using the $\Delta \Delta \mathrm{Ct}$ method. Mean and SD of each time point for each gene isoform is represented.

In the search for biomarkers to predict the therapeutic response to IFN $\beta$, ROC analyses were performed to evaluate the predictive discriminating value of TRAIL- $\alpha$, TRAIL- $\beta$ and TRAILR-1 expression on in vitro induction with IFN $\beta$ before treatment onset, on different cell subsets from patients with MS.

Values of areas under the curve (AUC), sensitivity, specificity, positive predictive value and negative predictive value are shown in table 3. Expression of TRAIL- $\alpha$ in the three cellular subsets better predicted those patients who will subsequently become non-responders to treatment, with AUC $>0.7$ and sensitivities greater than $80 \%$ in the three cases. Conversely, expression of TRAILR-1 on monocytes and CD4+ T cells better predicted those patients who will subsequently become responders to treatment, with AUC $>0.8$, sensitivities greater than $90 \%$ and specificities greater than $75 \%$. TRAIL- $\beta$ expression did not seem a good biomarker to predict therapeutic response to IFN $\beta$, as AUCs were under 0.7.

Effects of long-term IFN $\beta$ therapy on TRAIL and TRAIL receptors expression in PBMC from patients with MS

Relative expression of TRAIL and TRAIL receptors was significantly modified along the first year of therapy only for two genes. Expression of the isoform 2 of the death receptor TRAILR-2 was significantly reduced in monocytes from first- year responder as well as non-responder patients $(p=0.004$ and 0.016 , respectively). Expression of TRAIL- $\alpha$ was significantly increased in both $\mathrm{T}$ cell subsets but exclusively in patients who showed a clinical response to systemic IFN $\beta$ treatment ( $p=0.004$ in CD4 + cells and $p=0.002$ in CD8 + cells from responders). Induction of TRAIL- $\alpha$ mRNA expression in monocytes by IFN $\beta$ therapy was achieved in 13 of 24 responders and, therefore, overall expression in this subset was not significantly increased (figure 4).

\section{DISCUSSION}

TRAIL expression in PBMC has been proposed as a biomarker for therapeutic response to IFN $\beta$ in MS, ${ }^{5}$ but different splice variants were not taken into account. Several diseases have been related to alternative splice variant or aberrant splicing. ${ }^{20} \mathrm{We}$ hypothesise that alternative splice variants could be implicated in response to treatment and, thus, they should be measured independently.

In our study, we first determined the expression kinetics of TRAIL and its receptors' isoforms after in vitro stimulation with IFN $\beta$. In agreement with the existing literature, TRAIL isoforms reached a peak $4 \mathrm{~h}$ after IFN $\beta$ stimulation. ${ }^{12}$ Conversely, TRAIL receptors reached maximum expression at $24 \mathrm{~h}$ after induction. To the best of our knowledge, our group has been the first to
Figure 2 The Tumour necrosis factor-Related Apoptosis Inducing Ligand (TRAIL) $\alpha$ differential expression in healthy controls $(\mathrm{HC})$ and untreated patients with multiple sclerosis (MS). Expression levels are represented as relative expression compared with the reference gene GAPDH, using the $\Delta \Delta \mathrm{Ct}$ method. Figures show box plots: the horizontal bars are the median and lower and upper edges of the boxes represent the $25-75$ th centiles. Lines extending from the box are 10th and 90th centiles. The Mann-Whitney U test was used to determine statistical differences.

\section{CD14 ${ }^{+}$monocytes}
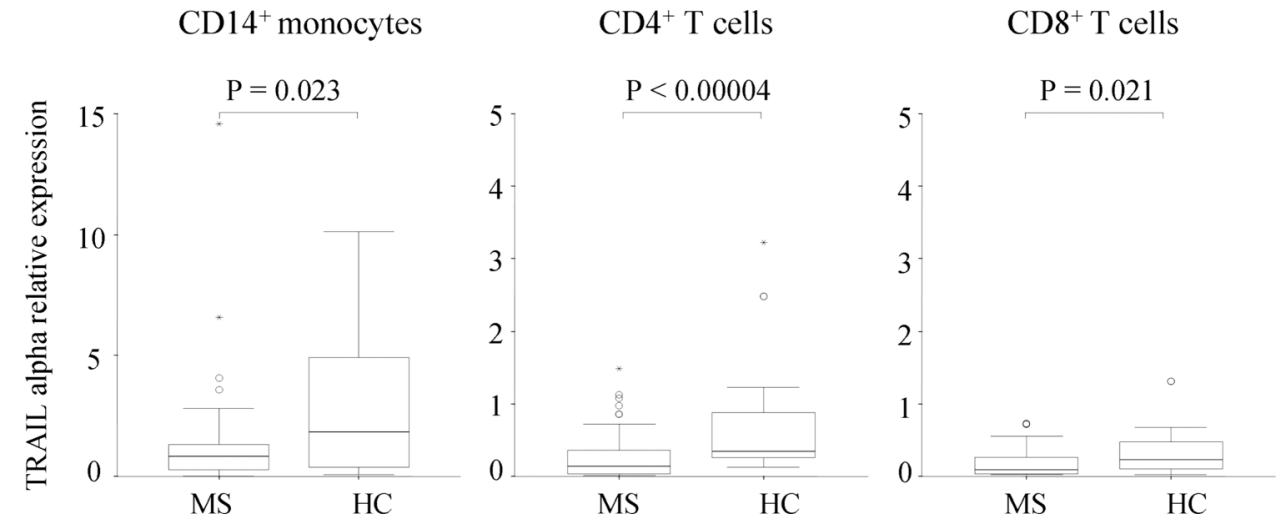
MONOCYTES
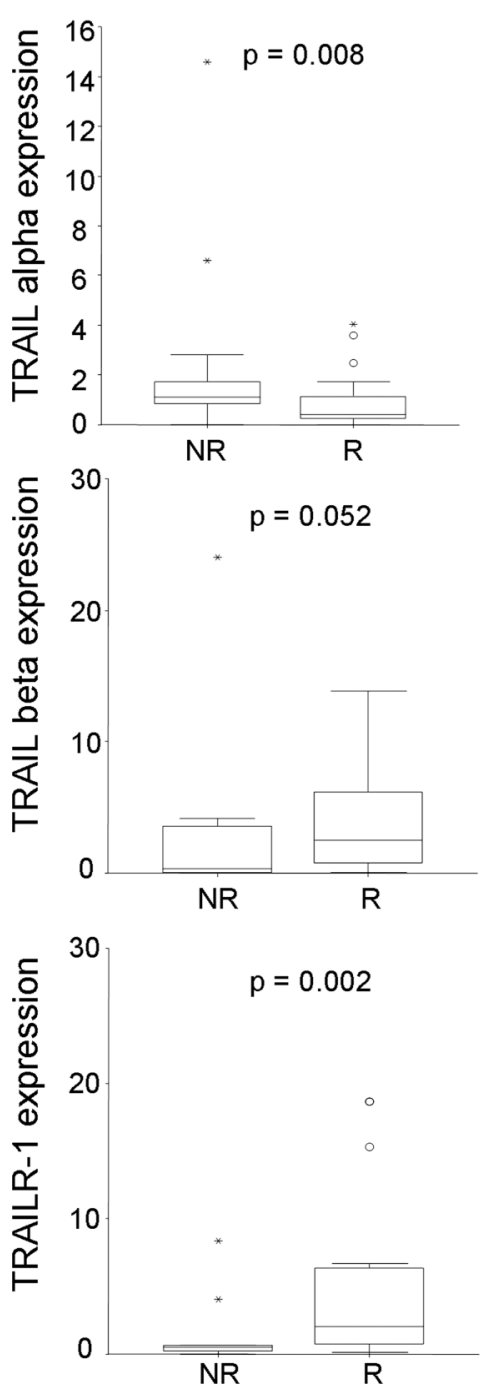

$\mathrm{CD4}^{+} \mathrm{T}$ CELLS
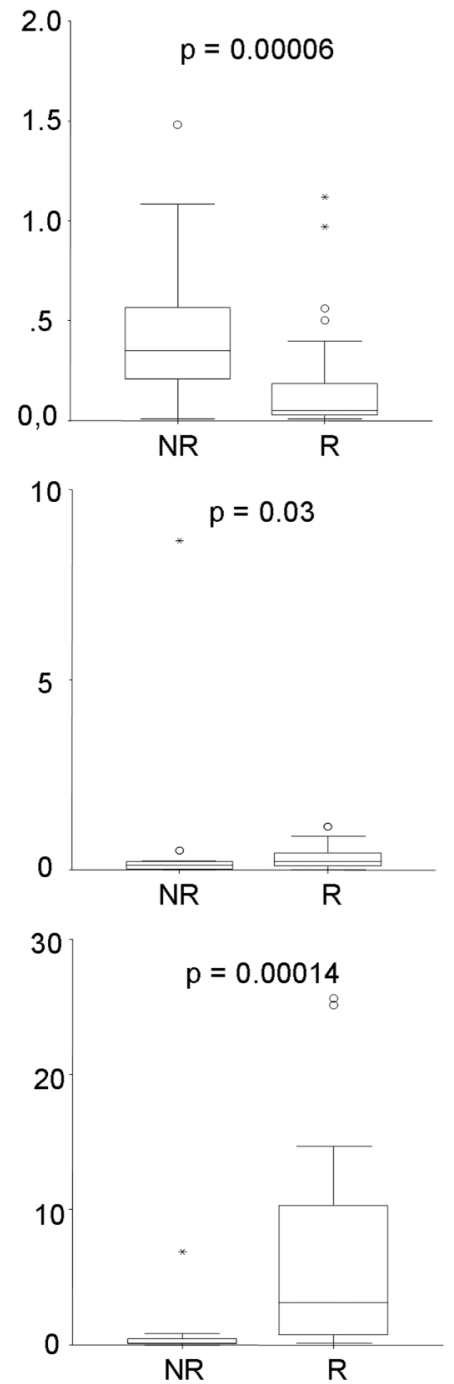

$\mathrm{CD}^{+} \mathrm{T}$ CELLS
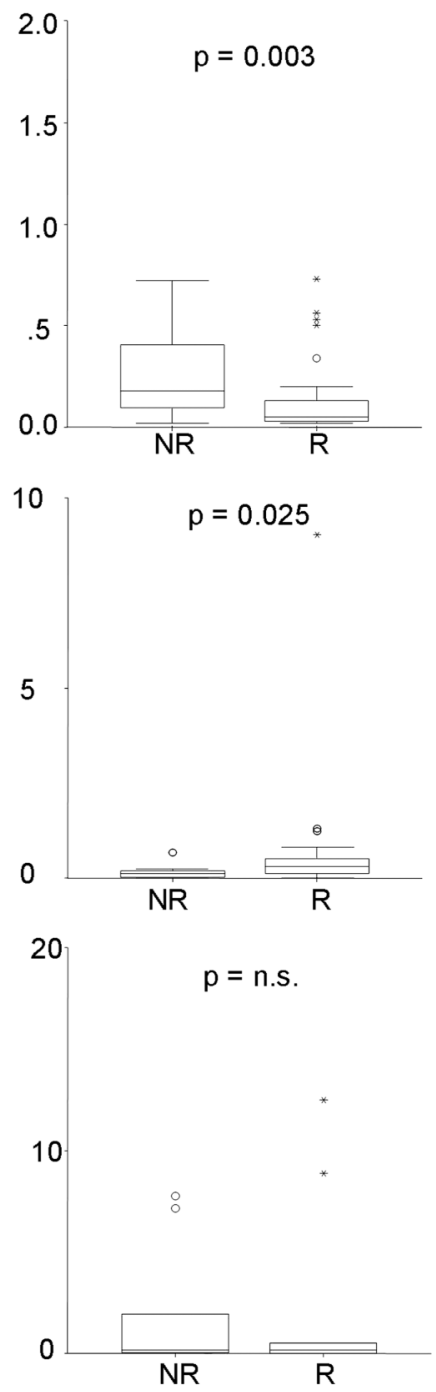

Figure 3 Relative expression of Tumour necrosis factor-Related Apoptosis Inducing Ligand (TRAIL) $\alpha$, TRAIL- $\beta$ and TRAILR-1, on in vitro stimulation with interferon $\beta$ (IFN $\beta$ ), before treatment onset. Those patients who will become non-responders (NR) to IFN $\beta$ therapy showed higher expression of TRAIL- $\alpha$ mRNA in the three cellular subsets, while those who will become responders (R) showed higher baseline expression of TRAIL- $\beta$ and TRAILR-1. Expression level is represented as relative expression compared with the reference gene GAPDH, using the $\Delta \Delta \mathrm{Ct}$ method. Figures show box plots: the horizontal bars are the median and lower and upper edges of the boxes represent the 25-75th centiles. Lines extending from the box are 10th and 90th centiles.

assess this issue. It remains unknown whether in vivo gene expression of TRAIL receptors after induction with IFN $\beta$ shares the same pattern as in vitro, or whether they go through a more complex regulation. We are currently performing a longitudinal study, using blood samples drawn at different time points after injection with IFN $\beta$, to address this question.

Contrary to previous studies, ${ }^{12} 21^{22}$ we found that the expression of TRAIL- $\alpha$ was significantly lower in monocytes and

Table 3 Sensitivity and specificity of biomarkers to predict the therapeutic response to IFN $\beta$

\begin{tabular}{|c|c|c|c|c|c|c|c|}
\hline Biomarker & Cell type & AUC & Cut-off & Sensitivity \% & Specificity \% & PPV \% & NPV \% \\
\hline \multicolumn{8}{|c|}{ Biomarkers that better predict suboptimal response: TRAIL- $\alpha$ expression on in vitro induction with IFN $\beta$, before the onset of IFN $\beta$ therapy } \\
\hline \multirow[t]{3}{*}{ TRAIL- $\alpha$} & Monocytes & 0.736 & 0.81 & 88.2 & 70 & 62.5 & 91.3 \\
\hline & CD4+ T cells & 0.794 & 0.12 & 83.3 & 65.2 & 55.5 & 88.2 \\
\hline & CD8+ $\mathrm{T}$ cells & 0.733 & 0.055 & 83.3 & 61.8 & 60.6 & 87.5 \\
\hline \multicolumn{8}{|c|}{ Biomarkers that better predict good response: TRAIL- $\beta$ and TRAILR-1 expression on in vitro induction with IFN $\beta$, before the onset of IFN $\beta$ therapy } \\
\hline \multirow{2}{*}{ TRAIL- $\beta$} & CD4+ T cells & 0.662 & 0.095 & 77.3 & 47.8 & 73.9 & 52.4 \\
\hline & CD8+ T cell & 0.683 & 0.115 & 71.1 & 52.6 & 75 & 47.6 \\
\hline \multirow[t]{2}{*}{ TRAILR-1 } & Monocytes & 0.803 & 0.67 & 90.5 & 78.6 & 79.2 & 81.8 \\
\hline & CD4+ T cells & 0.883 & 0.29 & 90 & 75 & 85.7 & 81.8 \\
\hline
\end{tabular}



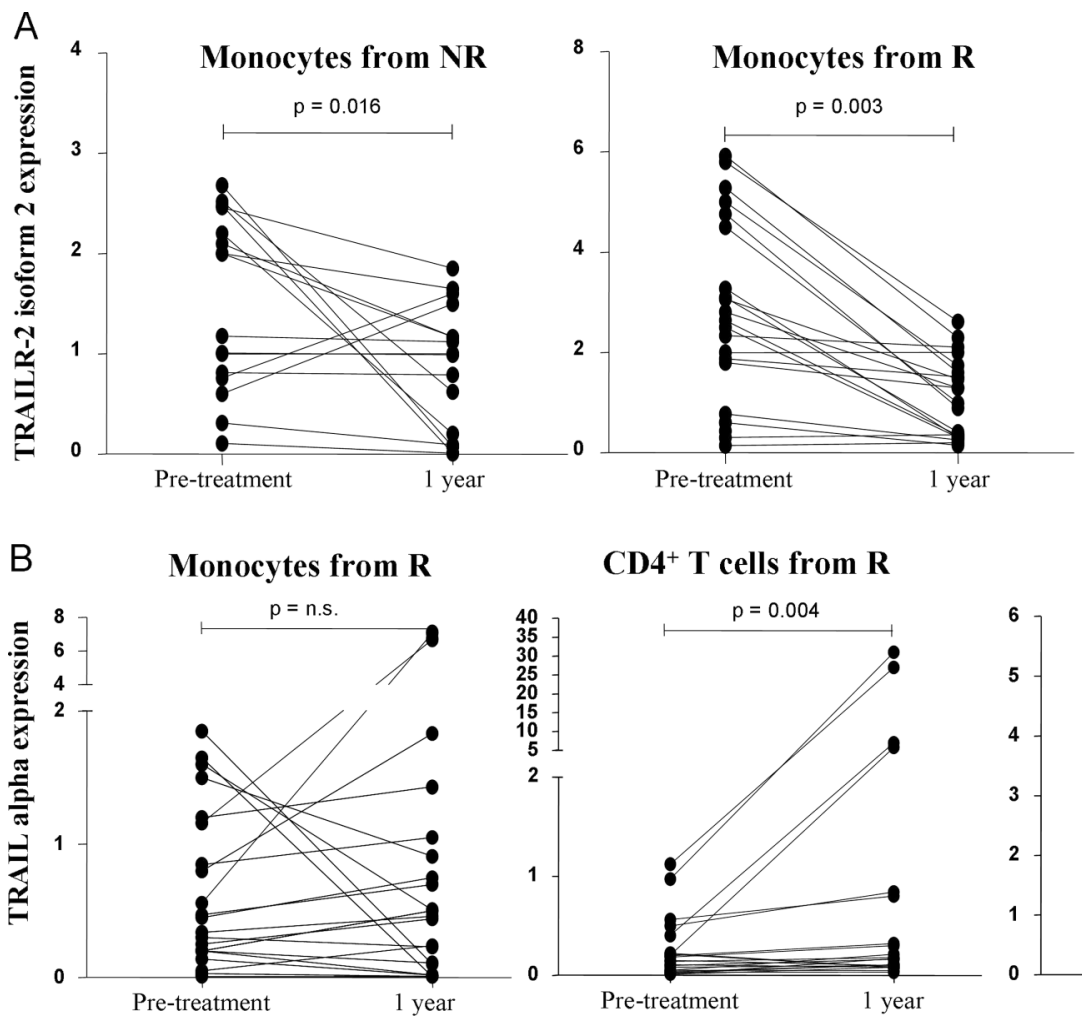

$\mathrm{CD4}^{+} \mathrm{T}$ cells from $\mathrm{R}$

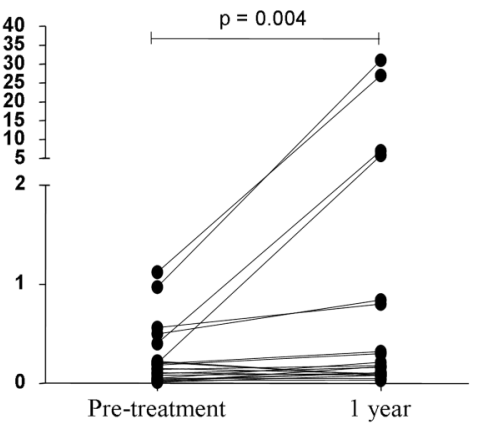

CD8 $^{+} \mathbf{T}$ cells from $\mathbf{R}$

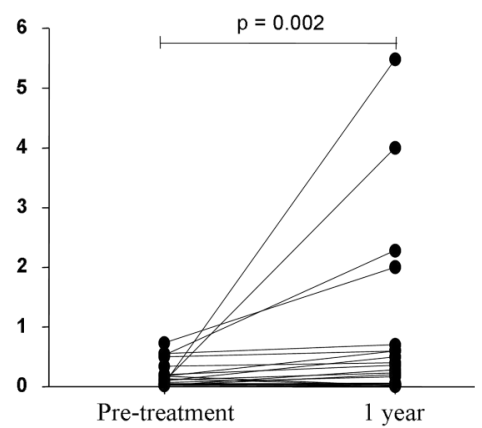

Figure 4 Effects of long-term treatment with interferon $\beta$ (IFN $\beta$ ) on Tumour necrosis factor-Related Apoptosis Inducing Ligand TRAILR-2 isoform 2 and TRAIL- $\alpha$ expression. Expression levels are represented as relative expression compared with the reference gene GAPDH, using the $\Delta \triangle C \mathrm{Ct}$ method. Expression before and after 1 year of IFN $\beta$ therapy in the same individual patients is plotted. (A) Long-term therapy with IFN $\beta$ significantly decreased mRNA expression of TRAILR-2 isoform 2 in monocytes from patients who will become responders (R) as well as those who will become non-responders (NR) to treatment. (B) TRAIL- $\alpha$ mRNA expression in CD4+ and CD8+ T cells significantly increased along with IFN $\beta$ therapy, but only in responders.

T cells from untreated patients with MS than from controls. In agreement, Kurne et al found lower soluble TRAIL concentrations in patients with MS than in HC. ${ }^{23}$ One possible explanation for this finding may be the lower levels of endogenous IFN $\beta$ reported in patients with $\mathrm{MS}^{24}$ which are unable to induce TRAIL synthesis to the same extent as they can in healthy subjects.

Cell type-specific induction of TRAIL by IFN $\beta$ in patients with MS has been reported. We have shown upregulation of TRAIL- $\alpha$ expression after IFN $\beta$ therapy in monocytes, and in CD4+ and CD8+ $\mathrm{T}$ lymphocytes. Earlier works found increased levels of TRAIL after IFN $\beta-1 \mathrm{a}$ injection only on the surfaces of monocytes and/or granulocytes. ${ }^{6825}$ However, upregulation of TRAIL expression in lymphocytes ${ }^{7} 26$ and T cell lines $^{28}$ from patients with MS and HC has also been reported. These differences could be attributed to the different culture conditions, kinetics and activation stimulus of the cells.

Within the patient group, those patients with MS who will be subsequently considered as responders to IFN $\beta$ therapy could be clearly distinguished from non-responders by baseline expression of TRAIL- $\alpha$ and TRAILR-1, indicating underlying differences in transcriptional regulation of these genes. The in vitro addition of IFN $\beta$ to previously IFN $\beta$ naïve cell subsets triggered a higher expression of TRAIL- $\alpha$ and a lower expression of TRAIL- $\beta$ in monocytes and T cells from patients who will continue to experience relapses or disease progression while treated with IFN $\beta$, and a higher expression of TRAILR-1 in monocytes and $\mathrm{CD} 4+\mathrm{T}$ cells from those who will have neither relapses nor progression of the disease. Wandinger $e t a l^{5}$ reported no differences in baseline expression of TRAIL regarding IFN $\beta$ responsiveness, but found higher baseline concentrations of soluble TRAIL in responders, findings that could not be replicated by others. ${ }^{29}$ Conversely, another study found higher levels of TRAIL in monocytes from relapsing-remitting quiescent disease patients (responders). ${ }^{8}$ Comparison among studies regarding biomarkers for therapeutic response to IFN $\beta$ in MS is difficult, due to the unique design and experimental approach of each single study.

It is known that TRAIL is upregulated on activation of monocytes $^{24} 30$ and T cells, ${ }^{28}{ }^{29}$ while TRAILR-1 and TRAILR-2, in turn, are downregulated on the RNA level when T cells are activated. ${ }^{28}$ In our ROC analysis, baseline TRAIL- $\alpha$ expression in the three cellular subsets at the cut-off levels described in table 3 predicts suboptimal response with a sensitivity greater than $80 \%$ and a specificity around $65 \%$, while baseline TRAILR-1 expression over 0.803 in monocytes and over 0.883 in CD4+ T cells predicts a good response to IFN $\beta$ therapy with a sensitivity higher than $90 \%$ and a specificity over $75 \%$, promoting the idea of using the expression of TRAIL- $\alpha$ and TRAILR- 1 as biomarkers to predict IFN $\beta$ treatment response. Probably, the changes in baseline expression of TRAIL- $\alpha$ and TRAILR- 1 of such a low magnitude in patients that will become non-responders may not be able to induce the expected changes after a significant increase in TRAIL, such as a strong inhibition of activation of autoreactive T cells, promotion of Tregs, or induction of neurons and oligodendrocytes apoptosis after lymphocyte infiltration. ${ }^{31}$ They may be more probably reflecting a compensatory mechanism to prevent, in part, the activation of autoreactive T cells in those untreated 
patients with an increased state of activation who will continue to experience relapses or progression. Another explanation for this increase in TRAIL- $\alpha$ expression at baseline in non-responders may be attributed to a comparatively higher pretreatment serum concentration of endogenous IFN $\beta$ in non-responders than responders, as shown by Axtell et al. ${ }^{32}$

Long-term treatment with IFN $\beta$ has been reported to increase TRAIL mRNA expression. ${ }^{5} 78{ }^{21}$ In our study, IFN $\beta$ therapy significantly increases TRAIL- $\alpha$ expression in both T cell subsets, but exclusively in responder patients, similar to results reported by others, ${ }^{58}$ reaching levels of expression that overcome those found in HC. In this sense, upregulation of TRAIL in responders contributes to the deletion of autoreactive lymphocytes, the inhibition of activation of autoreactive lymphocytes and limitation of the production of proinflammatory cytokines, mechanisms that may contribute to the clinical benefit of IFN $\beta$ therapy. Moreover, TRAIL- $\alpha$ promotes the induction of endogenous IFN $\beta,{ }^{33}$ amplifying its effects. Although TRAIL- $\alpha$ is also known to induce apoptosis of oligodendrocytes and neurons, as IFN $\beta$ enhances the integrity of the blood-brain barrier (BBB) in responders, the upregulation of TRAIL induced by IFN $\beta$ therapy probably comprises immunoregulatory mechanisms outside the central nervous system (CNS) more than apoptosis of brain cells.

However, although non-responders had higher basal TRAIL- $\alpha$ levels than responders, they showed an inability to increase TRAIL- $\alpha$ expression in T cells in response to IFN $\beta$ therapy, that is, these patients are already responding to endogenous IFN $\beta$, probably at maximum level, but still show a disease activity that obtains no benefit from further administration of IFN $\beta$. This inability to increase TRAIL- $\alpha$ expression could, on one hand, lead to a failure in the apoptosis of auto-aggressive T cells invading the CNS and, on the other hand, prevent inhibition of the activation of autoreactive $\mathrm{T}$ cells contributing to the perpetuation of the inflammatory response and the appearance of relapses and CNS damage.

Moreover, we found that long-term IFN $\beta$ therapy decreased the expression of TRAILR-2 isoform 2 in monocytes from patients with MS, regardless of the therapeutic responsiveness to this drug. Expression of TRAILR-2 is constitutive in peripheral blood leucocytes and may be involved in the apoptosis of activated lymphocytes ${ }^{22} 34$ and monocytes. In later stages of tissue pathology, macrophages outnumber T cells in CNS infiltrates and are needed to execute myelin phagocytosis in the demyelinating process. In this sense, downregulation of TRAILR-2 isoform 2 in monocytes could be one of the mechanisms responsible for the clinical benefits of IFN $\beta$, as apoptosis of peripheral monocytes will be prevented, allowing these cells to differentiate into macrophages, cross the BBB and exert their functions.

\section{CONCLUSIONS}

The present study shows that long-term therapy with IFN $\beta$ increased the expression of TRAIL- $\alpha$ in both T cell subsets exclusively from responder patients and decreased the expression of the isoform 2 of the death receptor TRAILR-2 in monocytes from responders as well as non-responders.

ROC analysis revealed that expression of TRAIL- $\alpha$ in the three cellular subsets, before the onset of IFN $\beta$ therapy, better predicted those patients who will subsequently become nonresponders to treatment while expression of TRAILR-1 on monocytes and CD4+ T cells better predicted those patients who will become responders.
Further studies are necessary in order to elucidate the pathways implicated in this process, which could reveal the precise mechanism by which IFN $\beta$ is exerting its beneficial effects on patients with MS, but TRAIL- $\alpha$ and TRAILR-1 should be assessed as predictors in future IFN $\beta$ responsiveness studies. However, inconsistent results among different studies regarding therapeutic biomarkers to IFN $\beta$ in MS make us evaluate our results with caution. To prove the effectiveness of these predictive markers, studies with larger sample sizes are warranted.

Acknowledgements The authors thank all the participants of this study. They also thank the "Red Española de Esclerosis Múltiple REEM (RD12/0032/0006)" and Fundación Española de Esclerosis Múltiple (FEDEM).

Contributors CL-G, BO-M, M-JP-M and MS performed the cellular subsets isolation, the gene expression analysis and the Nabs test. VR-G, PU and OF recruited the patients, evaluated the response to therapy and participated in the analyses. CL-G and LL designed the study, evaluated the results and wrote the manuscript. OF revised it critically for important intellectual content.

Funding The authors acknowledge the support from Fondo de Investigación Sanitaria \& Fondo Europeo de Desarrollo Regional (PS09/01764) and Consejería de Salud de la Junta de Andalucía (SAS07/0231) to LL. The authors would like to thank Biogen Idec Iberia SL for financial support.

Competing interests OF has received honoraria as consultant in advisory boards and as chairmen or lecturer in meetings, and has also participated in clinical trials and other research projects promoted by Biogen-Idec, Bayer-Schering, Merck-Serono, Teva, Novartis, Almirall and Allergan.

\section{Patient consent Obtained.}

Ethics approval Comisión de Ética y de Investigación del Hospital Regional Universitario Carlos Haya.

Provenance and peer review Not commissioned; externally peer reviewed.

Open Access This is an Open Access article distributed in accordance with the Creative Commons Attribution Non Commercial (CC BY-NC 4.0) license, which permits others to distribute, remix, adapt, build upon this work non-commercially, and license their derivative works on different terms, provided the original work is properly cited and the use is non-commercial. See: http://creativecommons.org/ licenses/by-nc/4.0/

\section{REFERENCES}

1 Rio J, Nos C, Tintore M, et al. Defining the response to interferon-beta in relapsing-remitting multiple sclerosis patients. Ann Neurol 2006;59:344-52.

2 Aktas 0, Schulze-Topphoff U, Zipp F. The role of TRAIL/TRAIL receptors in central nervous system pathology. Front Biosci 2007;12:2912-21.

3 Hoffmann 0, Zipp F, Weber JR. Tumour necrosis factor-related apoptosis-inducing ligand (TRAIL) in central nervous system inflammation. J Mol Med 2009;87:753-63.

4 Ikeda T, Hirata S, Fukushima $\mathrm{S}$, et al. Dual effects of TRAIL in suppression of autoimmunity: the inhibition of Th1 cells and the promotion of regulatory $T$ cells. J Immunol 2010;185:5259-67.

5 Wandinger KP, Lunemann JD, Wengert 0 , et al. TNF-related apoptosis inducing ligand (TRAIL) as a potential response marker for interferon-beta treatment in multiple sclerosis. Lancet 2003;361:2036-43.

6 Zula JA, Green HC, Ransohoff RM, et al. The role of cell type-specific responses in IFN-beta therapy of multiple sclerosis. Proc Natl Acad Sci USA 2011;108:19689-94.

7 Arbour N, Rastikerdar E, McCrea E, et al. Upregulation of TRAIL expression on human T lymphocytes by interferon beta and glatiramer acetate. Mult Scler 2005; 11:652-7.

8 Hebb AL, Moore CS, Bhan V, et al. Effects of IFN-B on TRAIL and Decoy Receptor Expression in Different Immune Cell Populations from MS Patients with Distinct Disease Subtypes. Autoimmune Dis 2010;2011:485752.

9 Krieg A, Krieg T, Wenzel M, et al. (2003) TRAIL-beta and TRAIL-gamma: two novel splice variants of the human TNF-related apoptosis-inducing ligand (TRAIL) without apoptotic potential. Br J Cancer 2003;88:918-27.

10 Valley CC, Lewis AK, Mudaliar DJ, et al. Tumor necrosis factor-related apoptosis-inducing ligand (TRAIL) induces death receptor 5 networks that are highly organized. J Biol Chem 2012;287:21265-78.

11 Krieg A, Schulte am Esch JII, Ramp U, et al. TRAIL-R4-beta: a new splice variant of TRAIL-receptor 4 lacking the cysteine rich domain 1. Biochem Biophys Res Commun 2006;349:115-21.

12 Gilli F, Marnetto F, Caldano M, et al. Biological markers of interferon-beta therapy: comparison among interferon-stimulated genes MXA, TRAIL and XAF-1. Mult Scler 2006;12:47-57. 
13 McDonald WI, Compston A, Edan G, et al. Recommended diagnostic criteria for multiple sclerosis: guidelines from the International Panel on the diagnosis of multiple sclerosis. Ann Neurol 2001;50:121-7.

14 Río J, Castilló J, Rovira A, et al. Measures in the first year of therapy predict the response to interferon $\beta$ in MS. Mult Scler 2009;15:848-53.

15 Oliver B, Orpez T, Mayorga C, et al. Neutralizing antibodies against IFN beta in patients with multiple sclerosis: a comparative study of two cytopathic effect tests (CPE) for their detection. J Immunol Methods 2009;351:41-5.

16 Kawade Y, Finter N, Grossberg SE. Neutralization of the biological activity of cytokines and other protein effectors by antibody: theoretical formulation of antibody titration curves in relation to antibody affinity. $J$ Immunol Methods 2003;278:127-44.

17 Chomczynski P, Sacchi N. Single-step method of RNA isolation by acid guanidinium thiocyanate-phenol-chloroform extraction. Anal Biochem 1987;162:156-9.

18 Oliver B, Mayorga C, Fernández $\mathrm{V}$, et al. Interferon receptor expression in multiple sclerosis patients. J Neuroimmunol 2007;183:225-31.

19 Rozen S, Skaletsky H. Primer3 on the WWW for general users and for biologist programmers. Methods Mol Biol 2000;132:365-86.

20 Solis AS, Shariat N, Patton JG. Splicing fidelity, enhancers, and disease. Front Biosci 2008;13:1926-42.

21 Rinta S, Kuusisto H, Raunio M, et al. Apoptosis-related molecules in blood in multiple sclerosis. J Neuroimmunol 2008;205:135-41.

22 Huang $W-X$, Huang MP, Gomes MA, et al. Apoptosis mediators fasL and TRAIL are upregulated in peripheral blood mononuclear cells in MS. Neurology 2000;55:928-34.

23 Kurne A, Guc D, Canpinar H, et al. Analysis of BAFF and TRAIL expression levels in multiple sclerosis patients: evaluation of expression under immunomodulatory therapy. Acta Neurol Scand 2011;123:8-12.

24 Wandinger $\mathrm{KP}$, Reissland $\mathrm{P}$, Kirchner $\mathrm{H}$, et al. Production of endogenous interferon-alpha and beta in patients with multiple sclerosis. J Neurol Neurosurg Psychiatry 1998;64:277-8.
25 Ehrlich S, Infante-Duarte C, Seeger B, et al. Regulation of soluble and surface-bound TRAIL in human T cells, B cells, and monocytes. Cytokine 2003;24:244-53.

26 Weber A, Wandinger KP, Mueller W, et al. Identification and functional characterization of a highly polymorphic region in the human TRAlL promoter in multiple sclerosis. J Neuroimmunol 2004;149:195-201.

27 Kayagaki N, Yamaguchi N, Nakayama M, et al. Type I interferons (IFNs) regulate tumor necrosis factor-related apoptosis-inducing ligand (TRAIL) expression on human T cells: a novel mechanism for the antitumor effects of type I IFNs. J Exp Med 1999;189:1451-60.

28 Wendling U, Walczak H, Dörr J, et al. Expression of TRAIL receptors in human autoreactive and foreign antigen-specific T cells. Cell Death Differ 2000;7:637-44.

29 Buttmann M, Merzyn C, Hofstetter HH, et al. TRAIL, CXCL10 and CCL2 plasma levels during long-term interferon-beta treatment of patients with multiple sclerosis correlate with flu-like adverse effects but do not predict therapeutic response. J Neuroimmunol 2007;190:170-6.

30 Halaas O, Vik R, Ashkenazi A, et al. Lipopolysaccharide induces expression of APO2 ligand/TRAIL in human monocytes and macrophages. Scand I Immunol 2000;51:244-50.

31 Matysiak $M$, Jurewicz $A$, Jaskolski $D$, et al. TRAIL induces death of human oligodendrocytes isolated from adult brain. Brain 2002; 125:2469-80.

32 Axtell RC, de Jong BA, Boniface $\mathrm{K}$, et al. T helper type 1 and 17 cells determine efficacy of interferon-beta in multiple sclerosis and experimental encephalomyelitis. Nat Med 2010;16:406-12.

33 Kumar-Sinha C, Varambally S, Sreekumar A, et al. Molecular cross-talk between the TRAIL and interferon signaling pathways. J Biol Chem 2002;277:575-85.

34 Barblu L, Herbeuval JP. Three-dimensional microscopy characterization of death receptor 5 expression by over-activated human primary CD4+ T cells and apoptosis. PLOS ONE 2012;7:e32874. 